\title{
SerpinB2 Deficiency Results in a Stratum Corneum Defect and Increased Sensitivity to Topically Applied Inflammatory Agents
}

Wayne A. Schroder, ${ }^{*}$ Itaru Anraku, ${ }^{*}$ Thuy T. Le, ${ }^{*}$ Thiago D.C. Hirata, ${ }^{\dagger}$ Helder I. Nakaya, ${ }^{\dagger}$ Lee Major, ${ }^{*}$ Jonathan J. Ellis, ${ }^{\ddagger}$ and Andreas Suhrbier*

\begin{abstract}
From the Inflammation Biology Group, * QIMR Berghofer Medical Research Institute, Brisbane, Queensland, Australia; the School of Pharmaceutical Sciences, ${ }^{\dagger}$ University of Sao Paulo, Sao Paulo, Brazil; and the University of Queensland Diamantina Institute, ${ }^{\ddagger}$ Translation Research Institute, Princess Alexandra Hospital, Woolloongabba, Queensland, Australia
\end{abstract}

\author{
Accepted for publication \\ February 18, 2016. \\ Address correspondence to \\ Andreas Suhrbier, Ph.D., QIMR \\ Berghofer, Locked Bag 2000, \\ Royal Brisbane Hospital, \\ Queensland 4029, Australia. \\ E-mail: andreas.suhrbier@ \\ qimrberghofer.edu.au.
}

\begin{abstract}
SerpinB2 (plasminogen activator inhibitor type 2) is constitutively expressed at high levels by differentiating keratinocytes in mice and humans; however, the physiological function of keratinocyte SerpinB2 remains unclear. Herein, we show that SerpinB2 $2^{-/-}$mice are more susceptible to contact dermatitis after topical application of dinitrofluorobenzene, and show enhanced inflammatory lesions after topical applications of phorbol ester. Untreated SerpinB2 ${ }^{-/}$mice showed no overt changes in epithelial structure, and we were unable to find evidence for a role for keratinocyte SerpinB2 in regulating immunity, apoptosis, IL-1 $\beta$ production, proteasomal activity, or wound healing. Instead, the phenotype was associated with impaired skin barrier function and a defective stratum corneum, with SerpinB2 $2^{-/-}$mice showing increased transepidermal water loss, increased overt loss of stratum corneum in inflammatory lesions, and impaired stratum corneum thickening after phorbol ester treatment. Immunoblotting suggested that SerpinB2 (cross-linked into the cornified envelope) is present in the stratum corneum and retains the ability to form covalent inhibitory complexes with urokinase. Data suggest that the function of keratinocyte SerpinB2 is protection of the stratum corneum from proteolysis via inhibition of urokinase, thereby maintaining the integrity and barrier function of the stratum corneum, particularly during times of skin inflammation. Implications for studies involving genetically modified mice treated with topical agents and human dermatological conditions, such as contact dermatitis, are discussed. (Am J Pathol 2016, 186: 1511-1523; http://dx.doi.org/10.1016/j.ajpath.2016.02.017)
\end{abstract}

SerpinB2 (alias plasminogen activator inhibitor type 2) is a member of the clade B or ovalbumin-like serine protease inhibitor (ov-serpin) subgroup of the serpin superfamily. SerpinB2 is expressed by a range of cells, including differentiating keratinocytes, cancer cells, monocytes/ macrophages, fibroblasts, endothelial cells, and dendritic cells, and is often up-regulated during inflammation. ${ }^{1-4}$ Despite $>1000$ articles in PubMed on SerpinB2/ plasminogen activator inhibitor type 2 , its physiological function remains unresolved, with this serpin labeled the undecided or enigmatic serpin. ${ }^{5-7}$

Extracellular SerpinB2 is widely described as an inhibitor of the extracellular protease urokinase plasminogen activator
(uPA) and (to a lesser extent) tissue plasminogen activator (tPA), with SerpinB2 (at least in vitro) acting as a suicide substrate to form a covalent SerpinB2-uPA or SerpinB2-tPA complex. ${ }^{4}$ tPA and uPA convert plasminogen to plasmin, a broad-spectrum protease involved in many processes, including inflammation and fibrinolysis, ${ }^{8}$ extracellular matrix degradation and cell migration/invasion, 9,10 wound healing, ${ }^{11}$ cleavage of specific cell surface proteins, ${ }^{12}$ and, if deregulated, tissue damage and disease. ${ }^{13-16} \operatorname{Serpin} 2^{-/-}$mice

\footnotetext{
Supported by grant APP1043104, National Health and Medical Research Council of Australia (W.A.S. and A.S.).

Disclosures: None declared.
} 
show no generalized/overt defects in plasminogen activation, and mice deficient in both SerpinB2 and plasminogen activator inhibitor type 1 show no additional plasminogen activation defects over those seen in plasminogen activator inhibitor type 1 deficient $\left(P A I-1^{-1-}\right)$ mice, ${ }^{17}$ with tPA/PA inhibition therefore conceivably restricted to specific settings. ${ }^{1}$

SerpinB2, like other ov-serpins, lacks a classic secretory signal peptide and is usually inefficiently secreted. ${ }^{18}$ However, in cancer cells and macrophages, efficient SerpinB2 secretion via microparticle formation was recently reported, providing at least one mechanism and setting whereby intracellular SerpinB2 can efficiently reach and inhibit extracellular uPA. ${ }^{10}$ Such microparticle-based secretion may explain the inhibitory effect of SerpinB2 expression on uPA-dependent migration and invasion. ${ }^{10,19}$ Macrophage SerpinB2 has also been associated with modulation of type $1 / 2$ helper T-cell responses in SerpinB2 $2^{-/-}$mice, ${ }^{10,20-23}$ a phenotype potentially also associated with microparticle secretion. $^{24}$

SerpinB2 has also been reported to have several ostensibly uPA-independent intracellular binding partners and activities, ${ }^{1}$ including negative regulation of NLRP3 inflammasome activation and IL- $1 \beta$ release, ${ }^{25,26}$ inhibition of calpain, ${ }^{27}$ inhibition of apoptosis, ${ }^{27,28}$ stabilization of transglutaminase $2,{ }^{29}$ and inhibition of the proteasome. ${ }^{30}$

Herein, we sought to gain insights into the physiological role of keratinocyte SerpinB2. Differentiating keratinocytes constitutively express high levels of SerpinB2, up to approximately $7000 \mathrm{ng} / \mathrm{mg}$ of total protein, whereas SerpinB2 is largely absent in simple epithelia. ${ }^{3,31}$ Changes in SerpinB2 distribution and/or expression have been reported for several skin conditions, including psoriasis, ${ }^{32}$ bullous pemphigoid, ${ }^{33}$ lupus, ${ }^{34}$ congenital ichthyosis, Netherton syndrome, ${ }^{35}$ chronic venous ulcers, ${ }^{36}$ scleroderma, ${ }^{37}$ and hyperkeratotic corn tissue. ${ }^{38}$ Several roles for keratinocyte SerpinB2 have been proposed, including regulation of growth and/or differentiation, ${ }^{39-42}$ inhibition of apoptosis, ${ }^{27,28,43}$ and inhibition of migration. ${ }^{44}$ SerpinB2 has also been proposed to regulate wound healing, ${ }^{4,36,45}$ although cutaneous wound healing (which involves keratinocyte migration) was unaffected in $\operatorname{SerpinB2} 2^{-1-}$ mice. ${ }^{17}$ SerpinB2 is largely retained intracellularly in living keratinocytes. ${ }^{46,47}$ During terminal differentiation of human keratinocytes, cytoplasmic SerpinB2 is covalently cross-linked by transglutaminase into the cornified envelope (CE) via glutamic acid residues (Gln83, Gln84, and $\mathrm{Gln} 86^{1}$ ) present in the large CD interhelical loop region of SerpinB2. ${ }^{47-49}$ Ultimately, the CE replaces the keratinocyte's plasma membrane and the resultant terminally differentiated corneocytes form the stratum corneum (SC), the uppermost lipid-rich skin layer essential for the physical and water barrier functions of the skin. ${ }^{49,50}$ Herein, we provide evidence that the physiological role of keratinocyte SerpinB2 is protection of the integrity of the $\mathrm{SC}$, particularly in inflammatory settings.

\section{Materials and Methods}

\section{Animal Ethics Statement}

All mouse work was conducted in accordance with good animal practice, as defined by the National Health and Medical Research Council of Australia. The mouse work was approved by the QIMR Berghofer Medical Research Institute animal ethics committee.

\section{DNFB Sensitization and Challenge}

Female SerpinB2 $2^{-1-}$ and SerpinB2 $2^{+/+}$mice (6 to 8 weeks old) were bred in-house at QIMR Berghofer Medical Research Institute. ${ }^{21}$ Dinitrofluorobenzene (DNFB) sensitization and challenge were performed essentially as described. ${ }^{51}$ Briefly, DNFB (Sigma, St. Louis, MO) [0.5\% $(\mathrm{w} / \mathrm{v})]$ in $100 \mu \mathrm{L}$ of an acetone-olive oil (4:1) mixture was applied to backs. Lesion scores were obtained by blind scoring of lesion images by three independent assessors, supplied with a reference series of lesion scores.

\section{Antimurine SerpinB2 Antibody}

An antimurine SerpinB2 antibody was generated in rabbits by Peptide Specialty Labs GmbH (Heidelberg, Germany), using the peptide ${ }^{62}$ EIGSYGITTRNPENFSGC ${ }^{79}$ (corresponding to the $\mathrm{N}$-terminal region of the $\mathrm{CD}$ loop of mouse SerpinB2) coupled to ovalbumin, with the antiserum affinity purified using the same peptide. [In our hands, current commercially available anti-SerpinB2 antibodies do not specifically recognize murine SerpinB2 (data not shown).]

\section{Histology}

Skin samples were fixed in $10 \%$ neutral buffered formalin and embedded in paraffin wax, and sections (6 mm thick) were cut and stained with hematoxylin and eosin. Sections were digitally scanned using the Aperio AT-Turbo (Leica Microsystems, North Ryde, Australia). Image analyses were undertaken using Aperio ImageScope software version 10 (Aperio Technologies, Vista, CA) and the Positive Pixel Count algorithm version 9 (Aperio Technologies).

\section{Immunohistochemistry}

Paraffin sections ( 3 to $4 \mu \mathrm{m}$ thick) were affixed to Menzel Superfrost Plus adhesive slides (Menzel GmbH, Braunschweig, Germany) and air dried overnight at $37^{\circ} \mathrm{C}$. Sections were dewaxed and rehydrated through descending graded alcohols to running tap water using standard protocols. After washing in phosphate-buffered saline, the sections were treated with 0.001 $\mathrm{mol} / \mathrm{L}$ EDTA/0.01 mol/L Tris buffer, $\mathrm{pH} \mathrm{8.8,} \mathrm{for} 15$ minutes at $105^{\circ} \mathrm{C}$, followed by washing. Endogenous peroxidase activity was blocked using $5 \% \mathrm{H}_{2} \mathrm{O}_{2}$ in phosphate-buffered saline for 10 minutes, followed by washing. Normal goat serum (10\%) was applied for 30 minutes, followed by the rabbit polyclonal 
anti-SerpinB2 antibody diluted 1:200 in phosphate-buffered saline for 1 hour at room temperature. After washing, Biocare Medical MACH2 Rabbit HRP was added for 30 minutes. After washing, color was developed using 3,3'-diaminobenzidine for 5 minutes. Sections were washed in tap water, lightly counterstained in Mayer's hematoxylin, dehydrated through ascending graded alcohols, cleared in xylene, and then mounted.

Apoptotic cells were stained using the ApoTag Plus Peroxidase In Situ Apoptosis Detection Kit (Millipore, Billerica, MA), according to the manufacturer's instructions. Slides were scanned and analyzed as above. Neutrophils were stained using anti-Ly6G, as described previously. ${ }^{52}$

\section{Immunoblotting of Skin and SC Preparations}

Full-thickness skin samples were cut from within the treatment sites and cut into small pieces and homogenized at $4^{\circ} \mathrm{C}$ using ceramic beads ( $2.8 \mathrm{~mm}$; MOBIO Labs, Inc., Carlsbad, CA) and a tissue homogenizer (Precellys 24, $6500 \mathrm{rpm}$, twice for 20 seconds) in $0.1 \%$ Igepal, $20 \mathrm{mmol} / \mathrm{L}$ HEPES, $\mathrm{pH} 7.5$, supplemented with cOmplete Protease Inhibitor Cocktail (Roche, Dee Why, Australia). The samples were then spun at top speed on a bench microfuge, and supernatants run on standard denaturing SDS-PAGE. Immunoblotting was performed using the antiSerpinB2 and anti- $\beta$-actin (rabbit, 13E5; Cell Signaling, Danvers, MA) antibodies. Resident peritoneal macrophages, which express high levels of SerpinB2, were prepared as described. $^{21}$ The secondary antibody was goat anti-rabbit horseradish peroxidase (Chemicon, Temecula, CA).

SC samples were collected by gently scraping the dampened skin surface of the mice at the treatment or control sites with a flat scalpel blade. The SC samples collected at the blade edge were scraped into $0.1 \% \mathrm{SDS}, 2 \mathrm{mmol} / \mathrm{L}$ EDTA, $20 \mathrm{mmol} / \mathrm{L}$ HEPES, pH 7.5, on ice. The samples were homogenized (Precellys 24$)$ and sonicated (20 seconds $\times 6$ ) and protein concentrations determined by standard Bradford protein assay (Bio-Rad, Hercules, CA). Samples $(15 \mu \mathrm{g})$ were run on a standard SDSPAGE and analyzed by immunoblotting, using anti-SerpinB2 and anti-uPA (rabbit anti-mouse uPA; Abcam, Cambridge, UK) antibodies, with the secondary antibody as above.

\section{TEWL, PMA Treatment, and Inflammation Scoring}

Transepidermal water loss (TEWL) was measured using the hand-held VapoMeter (Delfin Technologies Ltd, Kuopio, Finland); four readings were taken for each mouse at each time point. For phorbol 12-myristate 13-acetate (PMA) treatment, mice were shaved on the backs and 5 days later $10 \mu \mathrm{g}$ PMA was applied in $20 \mu \mathrm{L}$ of acetone daily for 3 days. Images of the lesions were taken and analyzed using Color Deconvolution Algorithm software version 9 (Aperio Technologies) to separate red (erythema) from brown/black (no erythema).

\section{Statistical Analysis}

Analyses were performed using IBM SPSS Statistics version 19 (Armonk, North Castle, NY). The $t$-test was used if the difference in the variances was $<4$, skewness was $>-2$, and kurtosis was $<2$. Where the data were nonparametric and difference in variances was $<4$, the Mann Whitney $U$ test was used, if $>4$ the Kolmogorov-Smirnov test was used. Where indicated, a repeat measures analysis of variance was used after log transformation of the data because of the differences in variance.

\section{Results}

\section{DNFB Irritant Contact Dermatitis Is More Severe in SerpinB2 $2^{-/-}$Mice}

To investigate the physiological function of keratinocyte SerpinB2, DNFB was topically applied to the skin of SerpinB2 $^{-1-}$ and $\operatorname{SerpinB2} 2^{+/+}$mice. DNFB is a hapten (widely used in models of irritant contact dermatitis and allergic contact hypersensitivity) that reacts with proteins in the skin, triggering innate proinflammatory responses, as well as adaptive T- and B-cell responses. ${ }^{53,54} \operatorname{SerpinB2} 2^{-1-}$ mice developed significantly more severe skin reactions than SerpinB2 $2^{+/+}$mice after a single topical treatment with DNFB (Figure 1). Skin reactions were scored (0 to 6) blind by three independent assessors, with minimal variation evident between assessors (Figure 1A). Skin reactions were significantly more severe in SerpinB2 $2^{-1-}$ (compared with SerpinB $2^{+/+}$) mice on multiple days after DNFB application in three independent experiments (Figure 1, B and C). Lesions in SerpinB2 $2^{+/+}$mice were largely restricted to mild patchy serous exudates, whereas lesions in SerpinB2 $2^{-/-}$ mice were generally characterized by robust and extensive eschar formation (Figure 1D).

\section{Histology and Immunohistochemistry of DNFB-Induced Lesions}

Hematoxylin and eosin staining showed that, in contrast with SerpinB2 $2^{+/+}$mice, SerpinB2 $2^{-1-}$ mice had more epidermis showing loss of SC after DNFB treatment (Supplemental Figure S1, A and B), consistent with the increased eschar formation seen in these mice (Figure 1C). These lesions in the SC were always associated with pronounced neutrophil infiltrates (Supplemental Figure S1A), with neutrophil recruitment to the skin after DNFB application well described. ${ }^{55}$ However, neutrophil recruitment to the treatment sites after DNFB application was not significantly different between $\operatorname{Serpin} 2^{-1-}$ and SerpinB2 $2^{+/+}$mice, as demonstrated by immunohistochemistry using quantitative image analysis (Supplemental Figure S1C) of anti-Ly6G antibody staining (Supplemental Figure S1D).$^{52}$ In neither SerpinB2 $2^{-/-}$nor SerpinB2 $2^{+/+}$ mice was there significant recruitment of macrophages (as determined by immunohistochemistry and F4/80 staining $^{52}$ ) to the DNFB treatment sites or to the epidermis apparent at 24, 48, or 72 hours after DNFB treatment (Supplemental Figure S2). 

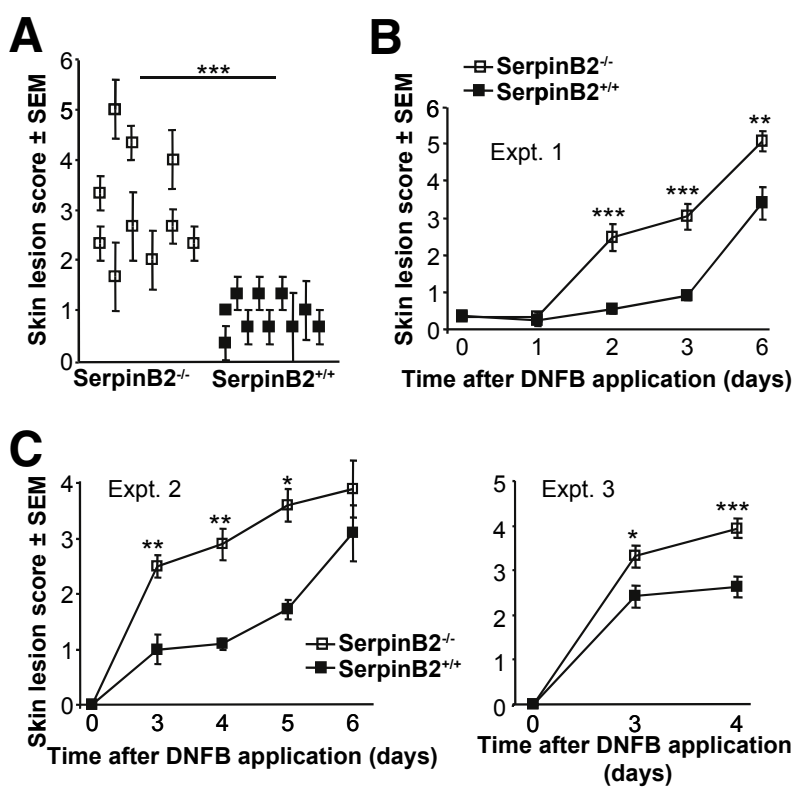

\section{D}

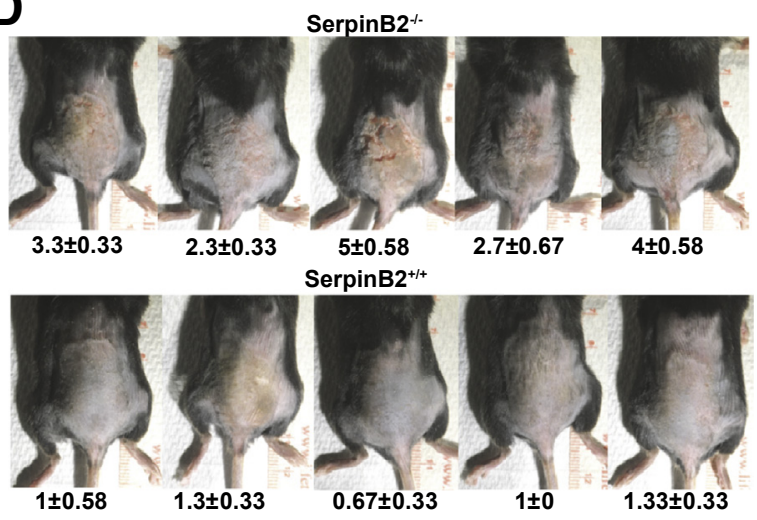

Figure 1 Skin reactions in SerpinB2-/- and SerpinB2 $2^{+/+}$mice after topical dinitrofluorobenzene (DNFB) treatment. A: Individual skin reaction severity scores for each of 10 SerpinB2 $2^{-/-}$and 10 SerpinB2 $2^{+/+}$mice on day 3 after topical $0.5 \%$ DNFB application. Values were established for each mouse from scores provided by three independent assessors. B: Mean skin reaction severity scores (mean of 10 mice per group) from Serpin $B 2^{-/-}$and SerpinB $2^{+/+}$mice over time after DNFB treatment. (Scoring as for $\mathbf{A}$; day 3 data derived from A). C: Two independent repeat experiments (set up as for B). D: Images of the treatment areas on the backs of the shaved mice showing five SerpinB2 $2^{+/+}$mice (top panels) and five SerpinB2 ${ }^{-/-}$mice (bottom panels). The skin reaction severity score for each mouse (three independent assessors) is shown bottom right of each image (each of these mice is represented in $\mathbf{A})$. Data are given as means $\pm \operatorname{SEM}(\mathbf{A}$ and $\mathbf{D}) . n=5$ mice per group [C, Expt. 2]; $n=8$ mice per group (C, Expt. 3 ). ${ }^{*} P<0.05$, ${ }^{* *} P \leq 0.01$, and ${ }^{* *} P \leq 0.001$. Expt., experiment.

\section{SerpinB2 Expression in Mouse Skin}

SerpinB2 is constitutively expressed by epidermal keratinocytes in both mice and humans, with levels in human keratinocytes up to approximately $7000 \mathrm{ng} / \mathrm{mg} .{ }^{1,3} \mathrm{We}$ generated a new polyclonal, affinity-purified, anti-mouse SerpinB2 antibody raised against the unique CD interhelical loop region of SerpinB2 (as described in Materials and Methods). Using this antibody, we were able to confirm the abundant intracellular expression of SerpinB2 in murine epidermal keratinocytes of SerpinB $2^{+/+}$mice before DNFB treatment (Figure 2A), with no other cell types in skin showing significant SerpinB2 staining (data not shown). The absence of significant staining in SerpinB2 ${ }^{-1-}$ mice illustrated the specificity of the antibody (Figure 2, B, D, F, and H). At 6 hours after DNFB application, SerpinB2 expression in SerpinB2 $2^{+/+}$mouse epidermis was substantially reduced, with some keratinocytes showing no SerpinB2 staining (Figure 2C) and some condensed SerpinB2 staining associated with degenerating cells (Figure 2C). At 24 hours (Figure 2E) and 48 hours (data not
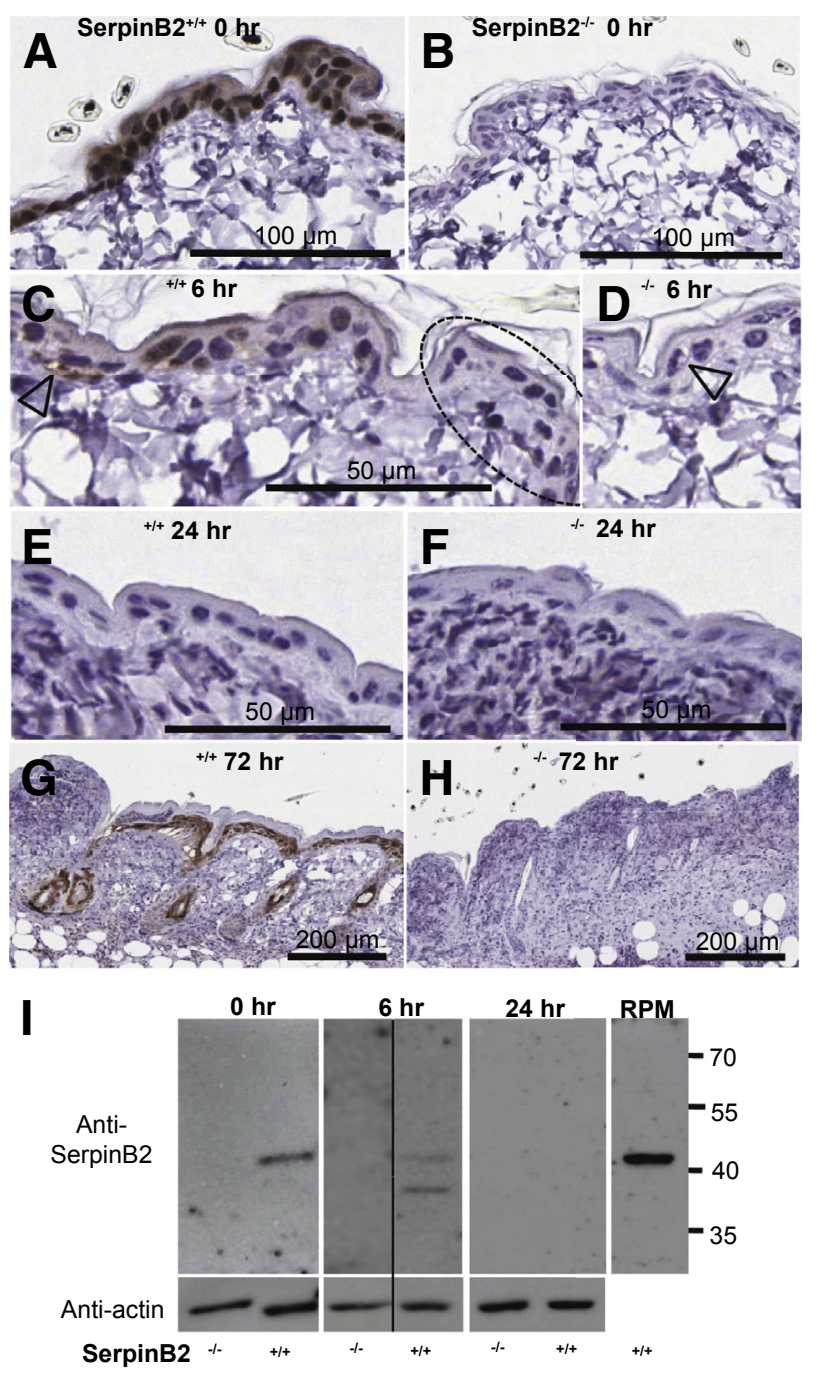

Figure 2 Immunohistochemistry and immunoblotting of skin from SerpinB2 $2^{-/-}$and SerpinB2 ${ }^{+/+}$mice after dinitrofluorobenzene (DNFB) application. Immunohistochemistry using anti-SerpinB2 antibody (and hematoxylin counter stain) of skin from SerpinB2 $2^{+/+}(\mathbf{A}, \mathbf{C}, \mathbf{E}$, and $\mathbf{G})$ and SerpinB2 $2^{--}(\mathbf{B}, \mathbf{D}, \mathbf{F}$, and $\mathbf{H})$ mice at the indicated times after application of DNFB. Dotted oval in $\mathbf{C}$ shows keratinocytes with loss of SerpinB2 staining. Arrowheads in $\mathbf{C}$ and $\mathbf{D}$ indicate keratinocytes with degenerating nuclei. I: Immunoblotting of skin samples from SerpinB2 $2^{+/+}$and SerpinB2 ${ }^{-/-}$mice at the indicated times after application of DNFB using anti-SerpinB2 and antiactin antibodies. Resident peritoneal macrophages (RPMs) were included as a positive control; these cells express high levels of SerpinB2. 
shown) after DNFB treatment, SerpinB2 staining of epidermis was lost. At 72 hours after DNFB, SerpinB2 staining reappeared in patches of regenerating epidermis (Figure 2G), consistent with previous findings. ${ }^{56}$ Western blotting of extracts from whole (full-thickness) skin samples showed the expected approximately $47-\mathrm{kDa}$ band in skin of SerpinB2 $2^{+/+}$mice, but not SerpinB2 $2^{-/-}$mice, with no other bands detected (Figure 2I). Primary resident peritoneal macrophages from SerpinB2 $2^{+/+}$mice express high levels of SerpinB2, ${ }^{21}$ and resident peritoneal macrophage lysates from SerpinB2 $2^{+/+}$mice, but not SerpinB2 $2^{-l-}$ mice, also showed the expected approximately $47-\mathrm{kDa}$ band, with no other bands detected (Figure 2I). The latter two immunoblotting experiments attest to the specificity of the antiSerpinB2 antibody. At 6 hours after DNFB treatment, a SerpinB2 cleavage product of approximately $40 \mathrm{kDa}$ appeared in skin lysates (Figure 2I), with loss of detectable expression evident at 24 hours (Figure 2I) and 48 hours (data not shown), consistent with the immunohistochemistry data (Figure 2E). N-terminal cleavage of SerpinB2 has been reported previously and has been associated with apoptosis, ${ }^{2,46,57}$ with keratinocyte apoptosis evident after DNFB treatment (see below). The polyclonal anti-SerpinB2 antibody was raised to a peptide (amino acids 62 to 79) from the $\mathrm{CD}$ loop region, suggesting an $\mathrm{N}$-terminal cleavage event is located just $\mathrm{N}$-terminal to, or just within, the $\mathrm{CD}$ loop region. ${ }^{1}$

These data thus confirm the expression of SerpinB2 protein in wild-type mouse keratinocytes, with SerpinB2 cleavage and loss after DNFB treatment consistent with keratinocyte apoptosis.

\section{Lesion Severity in SerpinB2 $2^{-/-}$Mice Is Not Associated with Changes in $\mathrm{T}$ - and $\mathrm{B}$-Cell Responses}

Mice were sensitized as above and then challenged with DNFB on the ear 6 days later, as per the standard contact hypersensitivity model. ${ }^{51,54}$ Skin lesions in the ears of SerpinB2 ${ }^{-1-}$ mice were again more severe (Supplemental Figure S3A), essentially recapitulating data shown in Figure 1. However, the ear swelling (using three different challenge doses of DNFB) was not different between SerpinB2 $^{-/-}$and SerpinB2 $2^{+/+}$mice (Supplemental Figure S3, $\mathrm{B}$ and $\mathrm{C}$ ). Because $\mathrm{T}$ cells are a primary driver of inflammation after challenge, ${ }^{54}$ these data do not support the notion that DNFB-induced T-cell activity was significantly altered in $\operatorname{Serpin} B 2^{-/-}$mice.

Antibodies also play a role in hapten-based contact hypersensitivity. ${ }^{58}$ However, no significant differences in anti-DNFB IgG1 or $\operatorname{IgG2c}$ responses $^{21,59}$ were apparent between SerpinB2 $2^{-/-}$and SerpinB2 $2^{+/+}$mice in two independent experiments (Supplemental Figure S4). Thus, in contrast with macrophage SerpinB2, ${ }^{1,20-23}$ these data suggest that keratinocyte SerpinB2 (at least in this setting) is not involved in modulating adaptive immune response. Adaptive immune responses are thus also unlikely to be responsible for the observations described in Figure 1.
Lesion Severity in SerpinB2-/- Mice Is Not Associated with Altered IL-1 Responses

Inflammasome activation and IL-1 $\beta$ release represents a prominent early keratinocyte response after DNFB application. ${ }^{53,60}$ SerpinB2 has been reported to inhibit IL-1 $\beta$ release $^{25,26}$; however, treatment with anakinra (an IL-1 receptor antagonist) did not significantly decrease the severity of the DNFB-induced skin lesions in SerpinB2 $2^{-1-}$ or SerpinB2 $2^{+/+}$mice (Supplemental Figure S5A). Furthermore, no increase in IL-1 $\beta$ processing was seen in skin of SerpinB2 $2^{-1-}$ mice after DNFB application (Supplemental Figure S5B), nor were the total levels of IL- $1 \alpha$ and IL-1 $\beta$ significantly different in skin from $\operatorname{Serpin} B 2^{-1-}$ and SerpinB $2^{+/+}$mice (Supplemental Figure S5C). These results do not support a role for keratinocyte SerpinB2 in regulating IL-1, and suggest IL-1 differences do not account for the exacerbated skin pathology shown in Figure 1.

The rate of lesion resolution after DNFB treatment was no different in SerpinB2 $2^{-/-}$and SerpinB2 $2^{+/+}$mice (irrespective of anakinra treatment) (Supplemental Figure S5D), consistent with the lack of a wound healing phenotype in SerpinB2 $2^{-1-}$ mice reported previously. ${ }^{17}$

\section{Lesion Severity in SerpinB2 $2^{-/-}$Mice Is Not Associated with Altered Keratinocyte Apoptosis}

A role for SerpinB2 in protection against apoptosis has been widely reported, ${ }^{27,61}$ although the literature is not consistent. ${ }^{1,10,43,62,63}$ Apotag staining revealed substantial levels of apoptosis in keratinocytes 6 hours after DNFB application (Supplemental Figure S6A). DNFB-induced apoptosis of keratinocytes has, to our knowledge, not previously been reported. However, Apotag staining levels were not significantly different between SerpinB2 $2^{-/-}$and SerpinB2 $2^{+/+}$ mice (Supplemental Figure S6B). Thus (in this setting), keratinocyte SerpinB2 does not appear to regulate apoptosis, suggesting differences in apoptosis are not responsible for the observations in Figure 1.

\section{No Overt Differences in Epidermal Structure in SerpinB2 $2^{-/-}$Mice}

Several articles have suggested that SerpinB2 has a role in regulating keratinocyte growth and/or differentiation. ${ }^{39-42}$ However, hematoxylin and eosin staining of foot pads (which have a much thicker epidermis than normal mouse skin) showed no overt differences in the structure of the epidermis or the SC from untreated SerpinB2 $2^{-/-}$and SerpinB2 ${ }^{+/+}$mice (Figure 3B), consistent with a previous study. ${ }^{17}$

SerpinB2 staining of foot pads illustrated that SerpinB2 protein expression was lower in the basal cells than the suprabasal stratifying cells (Figure 3C), a pattern similar to that seen in human skin. ${ }^{32,34,35}$ Staining of the SC with the antiSerpinB2 antibody was not generally observed (Figure 3C), except on rare occasions (Supplemental Figure S6C). 

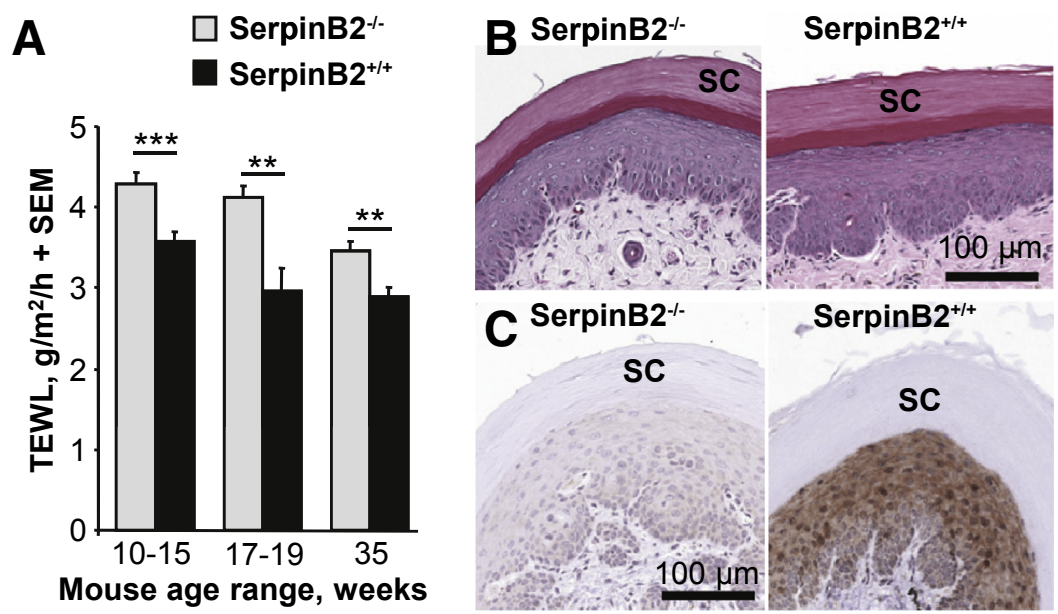

Figure 3 Transepidermal water loss (TEWL), histology, and immunohistochemistry of untreated skin from SerpinB2 $2^{-/-}$and SerpinB2 $2^{+/+}$mice. A: TEWL was measured from the belly skin (unshaved) of SerpinB2 ${ }^{+/+}$ and SerpinB2 ${ }^{-1-}$ mice. Statistics by $t$-tests. B: Hematoxylin and eosin staining of footpads from SerpinB2 ${ }^{-/}$ and SerpinB $2^{+/+}$mice. C: Immunohistochemistry of footpads from SerpinB2 ${ }^{-/-}$and SerpinB2 ${ }^{+/+}$mice with anti-SerpinB2 antibody. $n=20$ (A, aged 10 to 15 weeks); $n=8$ (A, aged 17 to 19 weeks); $n=4$ to 7 (A, aged 35 weeks). ${ }^{* *} P \leq 0.01,{ }^{* * *} P<0.001$. SC, stratum corneum.

\section{No Evidence for SerpinB2 Deficiency Changing Proteasome Activity}

SerpinB2 has been reported to bind the proteasomal subunit member $\beta 1,{ }^{2,64}$ with a report also suggesting SerpinB2 can inhibit proteasome activity. ${ }^{30}$ In an extensive series of experiments, we were unable to show a consistent or significant effect of SerpinB2 expression on proteasomal enzyme activities (Supplemental Figure S7).

\section{Microarray Analysis of Normal Skin from SerpinB2 ${ }^{-/-}$ and SerpinB2 ${ }^{+/+}$Mice}

To gain insights into the cell type(s) and processes in the skin potentially dysregulated by SerpinB2 deficiency, microarray analysis $^{65}$ of normal skin from SerpinB2 $2^{-/-}$and SerpinB2 $2^{+/+}$ mice was undertaken. Only a handful of genes were significantly up-regulated or down-regulated in $\operatorname{Serpin} B 2^{-/-}$mice by more than twofold (Supplemental Table S1). This mild effect on gene expression is perhaps consistent with the normal skin structure and wound healing seen in SerpinB2 ${ }^{-1-}$ mice. DAVID Functional Annotation Clustering analysis illustrated that genes down-regulated in SerpinB2 $2^{-1-}$ skin were significantly associated with keratinocytes and keratinocyte differentiation, including keratinization and cornification (Supplemental Table S2). Keratinocytes express functional olfactory receptors, ${ }^{66-68}$ which can sense odorants $^{66,69}$ and be up-regulated by allergens ${ }^{70}$; and DAVID analysis of up-regulated genes identified genes associated with olfactory receptors as being up-regulated in SerpinB2 $2^{-/-}$ skin (Supplemental Table S2). These results suggest that the differences in the skin of SerpinB2 $2^{-/-}$and SerpinB2 $2^{+/+}$mice largely resided within the keratinocyte population [rather than other cell type within the skin (eg, fibroblasts, endothelial cells, or macrophages, which can also express SerpinB2)] and that SerpinB $2^{-1-}$ mice might have a CE/SC defect given that the processes described in Supplemental Table S2 are associated with terminal differentiation of keratinocytes and the formation of the $\mathrm{CE} / \mathrm{SC}$.

\section{Increased TEWL in SerpinB2 $2^{-/-}$Mice}

During the terminal differentiation of keratinocytes, SerpinB2 is cross-linked by transglutaminase into the $\mathrm{CE}^{47,48}$ via glutamic acid residues in the $\mathrm{CD}$ loop region, ${ }^{35}$ with the $\mathrm{CEs}$ ultimately forming the SC. The importance of an intact skin barrier function for limiting the sensitivity to hapten-induced contact dermatitis is widely accepted, ${ }^{53,71}$ with the SC largely responsible for the skin barrier function. ${ }^{49}$ Because the microarray analysis suggested a CE/SC defect, skin barrier function was investigated by measuring TEWL. ${ }^{72} \mathrm{~A}$ significant and consistent $15 \%$ to $30 \%$ increase in TEWL was apparent in SerpinB2 $2^{-1-}$ mice, with TEWL decreasing with age (Figure 3A and Supplemental Figure S8A). SerpinB2 deficiency in keratinocytes thus results in an impaired skin barrier function, an observation that would explain increased sensitivity to topically applied haptens.

\section{TEWL and Inflammation after Topical PMA Treatment of SerpinB2 ${ }^{+/+}$and SerpinB2 ${ }^{-/-}$Mice}

Topical application of PMA is known to up-regulate both SerpinB2 expression and the normally low uPA expression in the epidermis. ${ }^{73}$ SerpinB2 $2^{+/+}$and SerpinB2 $2^{-1-}$ mice were thus treated topically with PMA (days 0,1 , and 2) and TEWL monitored. The initial $11 \%$ higher TEWL in SerpinB2 $^{-1-}$ (compared with SerpinB2 $2^{+/+}$) mice increased to a mean $27 \%$ (range, $8 \%$ to $48 \%$ ) difference between days 2 and 9 after treatment initiation (Figure 4A). PMA treatment thus exacerbated the differences in TEWL between SerpinB2 $^{+/+}$and SerpinB2 $2^{-/-}$mice. The rate of TEWL recovery after PMA treatment cessation was similar in SerpinB2 $2^{+/+}$and SerpinB2 $^{-1-}$ mice (Figure 4A and Supplemental Figure S5E), again consistent with the lack of a wound healing phenotype in SerpinB2 $2^{-1-}$ mice.

In the same experiment, digital images of the PMA treatment sites were taken (Supplemental Figure S8B) and erythema (red color) quantitated by Color Deconvolution Algorithm software version 9. The red erythema score was 


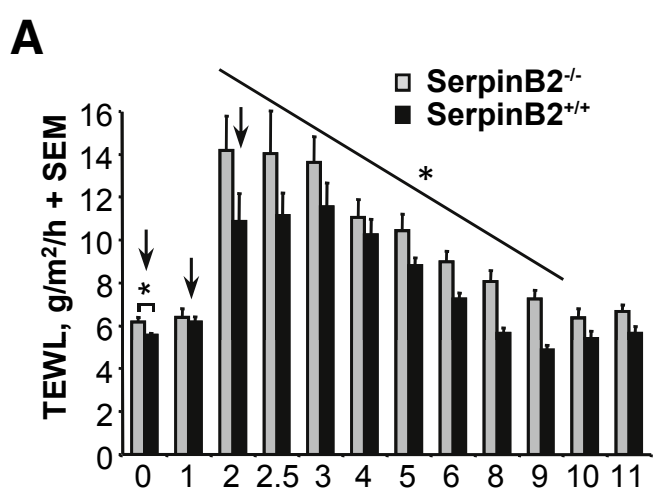

Time after treatment initiation (days)

C
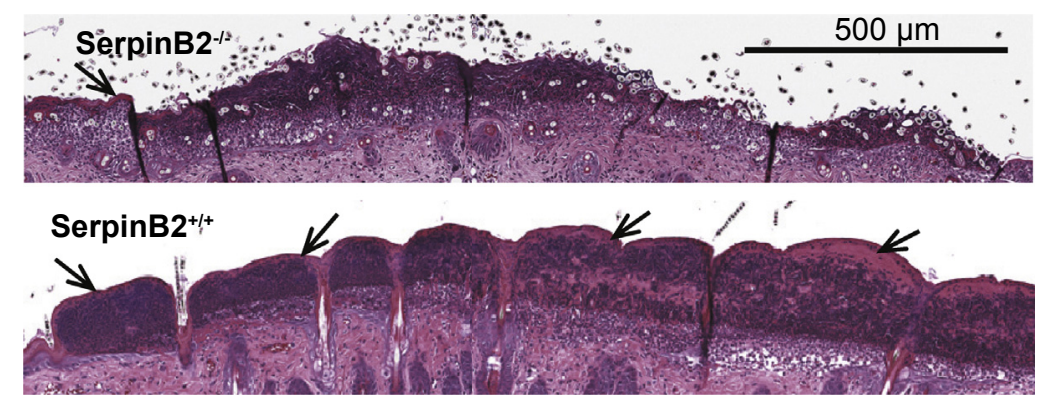

D

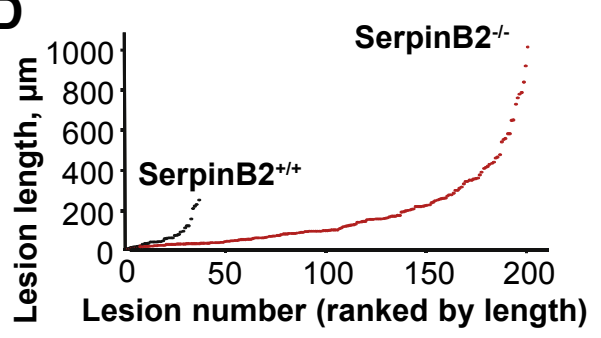

B

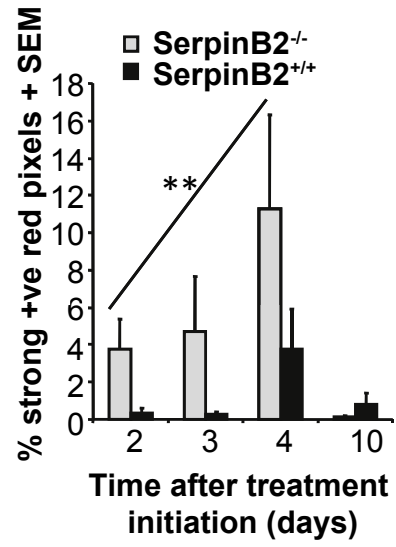

E

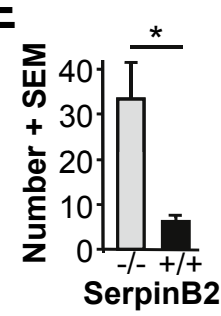

$\mathbf{F}$

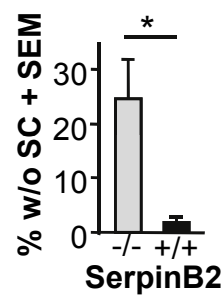

Figure 4 Skin treatment with phorbol 12myristate 13 -acetate (PMA). A: SerpinB2 ${ }^{-1-}$ and Serpin $2^{+/+}$mice were treated topically with PMA three times (at the times indicated by arrows) and transepidermal water loss (TEWL) measured at the treatment sites. Statistics: differences on day 0 between SerpinB2 $2^{-/-}$and SerpinB2 $2^{+/+}$mice determined by $t$-test; differences on days 2 to 7 between SerpinB2 $2^{-/-}$and SerpinB2 $2^{+/+}$mice determined by repeated measures analysis of variance. B: PMA treatment as for A, with erythema (red pixels) quantitated by color deconvolution software from images of skin lesions (Supplemental Figure S8B). Statistics by repeated measures analysis of variance. C: Hematoxylin and eosin (H\&E) staining of treatment sites on day 2.5 ( 6 hours after last PMA treatment). Arrows indicate intact stratum corneum (SC). D: Length and number of lesions without SC with each lesion plotted as a single dot: black for SerpinB2 ${ }^{+/+}$ and red for SerpinB2 ${ }^{-/}$(two H\&E sections per mouse). E: Statistical treatment of data from D comparing mean number of skin lesions where SC was absent. Statistics by Kolmogorov-Smirnov test. F: Statistical treatment of data from D comparing mean percentage of skin section lengths where SC was absent. Statistics by KolmogorovSmirnov test. $n=6$ per group (A and $\mathbf{D})$. ${ }^{*} P<0.05,{ }^{* *} P<0.01$. significantly higher in SerpinB2 $2^{-1-}$ compared with

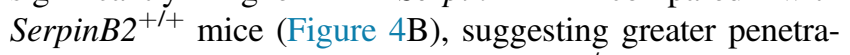
tion of PMA across the SC in SerpinB2 $2^{-l-}$ mice.

\section{Increased Loss of SC after PMA Treatment of SerpinB2 $2^{-/-}$Mice}

Mice were treated with PMA, as described above, and lesions were examined by hematoxylin and eosin. In SerpinB2 $2^{-1-}$ mice, the SC was frequently absent, in particular in areas containing high numbers of neutrophils, which are efficiently recruited by PMA treatment. ${ }^{74}$ The presence of neutrophils was again confirmed by anti-Ly6G staining (data not shown). In such neutrophil-rich areas in SerpinB2 $2^{+/+}$mice, the SC remained largely intact (Figure 4C). After PMA treatment, Serpin $B 2^{-l-}$ mice showed more, and longer, skin section lengths with overt loss of SC (Figure 4D). Both the number of lesions (Figure 4E) and percentage of skin section lengths without SC (Figure 4F) were significantly different between $\operatorname{SerpinB}^{+/+}$and SerpinB2 $2^{-/-}$mice.

\section{Epidermal and SC Thickening after PMA Treatment}

Topical PMA application is known to cause keratinocyte hyperproliferation, resulting in thickening of the epidermal layer, ${ }^{75,76}$ and promote terminal differentiation of keratinocytes, resulting in thickening of the SC..$^{77}$ The thickening of the epidermal cell layers was not significantly different between $\operatorname{SerpinB} 2^{+/+}$and SerpinB2 $2^{-l-}$ mice after PMA treatment (Figure 5, A and C). However, the significant thickening of the SC seen in SerpinB2 $2^{+/+}$mice (after PMA) was not seen in SerpinB2 $2^{-1-}$ mice (Figure 5, B and C). Thus, under inflammatory conditions known to induce uPA, an overt SC defect was apparent in SerpinB2 $2^{-1-}$ mice.

\section{Detection of SerpinB2 and UPA in SC Extracts by Immunoblotting}

To determine whether murine SerpinB2 (like human SerpinB2) is present in the SC, SC samples were analyzed by immunoblotting. SC samples were collected by gently 

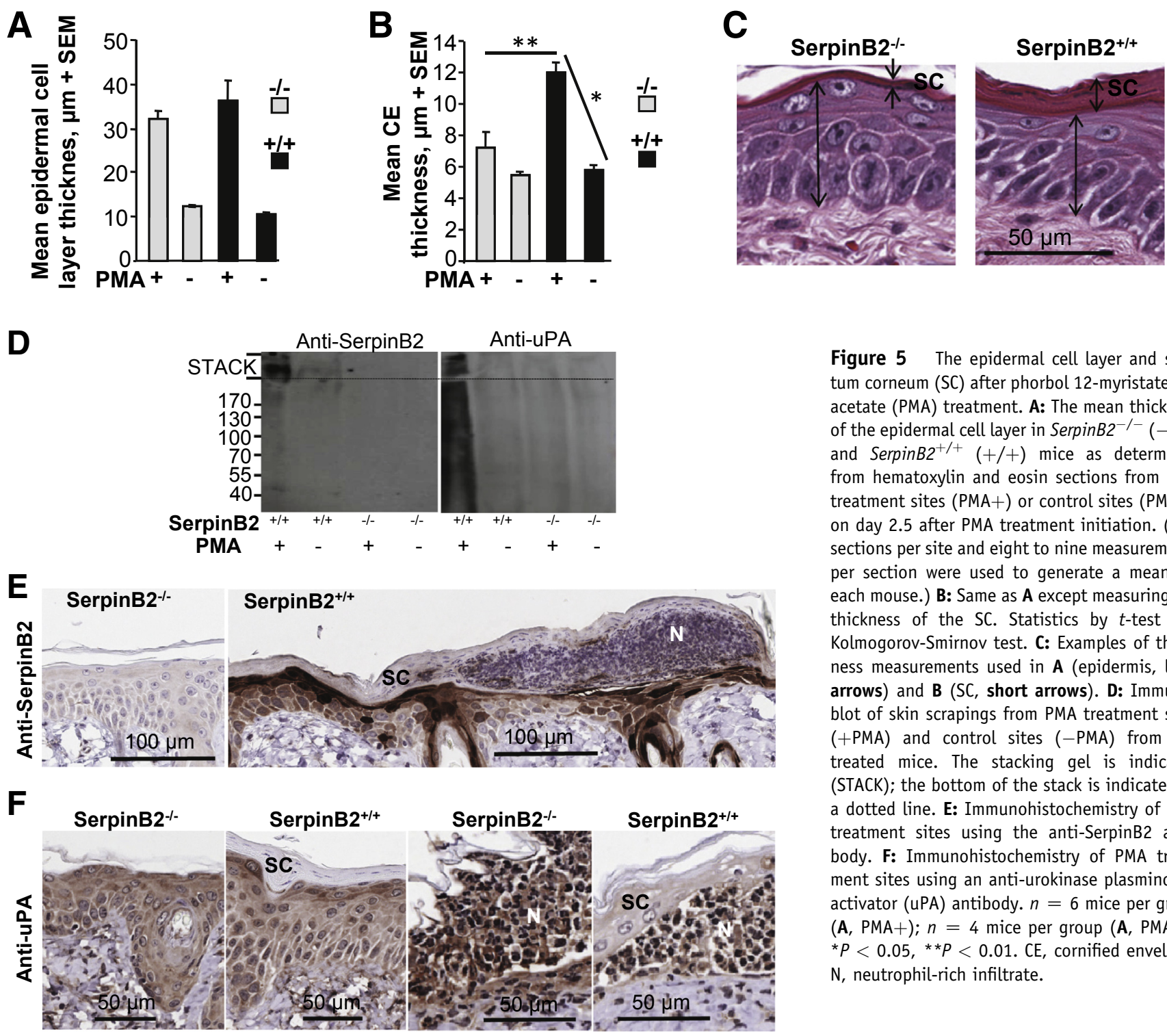

\begin{abstract}
Figure 5 The epidermal cell layer and stratum corneum (SC) after phorbol 12-myristate 13acetate (PMA) treatment. A: The mean thickness of the epidermal cell layer in SerpinB2 ${ }^{-/-}(-/-)$ and SerpinB2 $2^{+/+}(+/+)$mice as determined from hematoxylin and eosin sections from PMA treatment sites $(\mathrm{PMA}+)$ or control sites (PMA-) on day 2.5 after PMA treatment initiation. (Two sections per site and eight to nine measurements per section were used to generate a mean for each mouse.) B: Same as $\mathbf{A}$ except measuring the thickness of the SC. Statistics by $t$-test and Kolmogorov-Smirnov test. C: Examples of thickness measurements used in $\mathbf{A}$ (epidermis, long arrows) and $\mathbf{B}$ (SC, short arrows). D: Immunoblot of skin scrapings from PMA treatment sites (+PMA) and control sites (-PMA) from untreated mice. The stacking gel is indicated (STACK); the bottom of the stack is indicated by a dotted line. E: Immunohistochemistry of PMA treatment sites using the anti-SerpinB2 antibody. F: Immunohistochemistry of PMA treatment sites using an anti-urokinase plasminogen activator (UPA) antibody. $n=6$ mice per group $(\mathrm{A}, \mathrm{PMA}+) ; n=4$ mice per group (A, PMA-). ${ }^{*} P<0.05,{ }^{*} P P<0.01$. CE, cornified envelope; $\mathrm{N}$, neutrophil-rich infiltrate.
\end{abstract}

scraping the surface of dampened skin with a flat scalpel blade. In multiple experiments, high-molecular-weight antiSerpinB2 reactive bands were detected in the stacking gel, which were significantly more prominent in SC samples from SerpinB2 $2^{+/+}$mice after PMA treatment, and were undetectable in samples from SerpinB2 $2^{-/-}$mice (Figure 5D and Supplemental Figure S8C). The proteins in the SC exist as large covalently cross-linked complexes and would thus not be expected to migrate far into a polyacrylamide gel. When the same SC samples were analyzed with an anti-uPA antibody, high-molecular-weight bands in the stacking gel were also apparent in samples from SerpinB $2^{+/+}$mice after PMA treatment, but not in SC samples from SerpinB2 ${ }^{-1-}$ mice (Figure 5D). The former also showed a long uPAreactive smear in the separating gel (Figure 5D). A smear was also faintly visible when this sample was immunoblotted with the anti-SerpinB2 antibody (Figure 5D). These smears suggest degradation of the SC, perhaps by one or more of the $>30$ proteases expressed by keratinocytes and/or infiltrating inflammatory cells. ${ }^{78}$

The results (Figure 5D) thus support the view that SerpinB2, which is covalently cross-linked to proteins in the $\mathrm{SC}$, retains the ability to generate covalent inhibitory complexes with uPA, thereby covalently attaching uPA (via SerpinB2) to the proteins in the SC. (The CD loop is known to be dispensable for uPA inhibition. ${ }^{79}$ ) Thus, in SerpinB2 $2^{-1-}$ mice, although uPA is present (Figure 5F), because of the absence of cross-linked SerpinB2, uPA does not become covalently attached to the SC.

Immunohistochemistry after PMA with Anti-SerpinB2 and UPA Antibodies

Anti-SerpinB2 antibody staining of skin sections from SerpinB $2^{+/+}$mice after PMA treatment illustrated strong SerpinB2 expression in the upper layers of the epidermis 
(Figure 5E). Some staining of the $\mathrm{CE}$ was also evident (Figure 5E); the tightly packed lipid-rich lamellar bodies in the SC may limit antibody access. In contrast to previous reports (reviewed by Schroder et $\mathrm{al}^{1}$ ), we were unable to see significant SerpinB2 protein expression in neutrophils (Figure 5E).

As expected, ${ }^{73}$ uPA expression was clearly evident in keratinocytes after PMA treatment, and was similar in both mouse strains (Figure 5F). However, staining was particularly pronounced in the infiltrating neutrophils (Figure 5F), with uPA expression by neutrophils well established in other settings. ${ }^{80}$ Normal rabbit serum controls showed no significant staining (data not shown). The loss of SC in Serpin $B 2^{-1-}$ mice was nearly always associated with the presence of neutrophils in the epidermal layer. Thus, both keratinocytes and infiltrating neutrophils provide a source of uPA after PMA treatment.

\section{Discussion}

Herein, we show for the first time that a physiological function of keratinocyte SerpinB2 is protection of the SC and its barrier function, an activity particularly evident during skin inflammation. The skin of SerpinB2 $2^{-1-}$ mice showed increased TEWL and increased sensitivity to cutaneous applications of irritants, with an intact barrier function key to limiting water loss and penetration of chemicals into the skin. ${ }^{49,53,71,81}$ Furthermore, PMA-induced thickening of the SC did not occur in SerpinB2 $2^{-/-}$mice, and SerpinB2 $2^{-/-}$ mice experienced loss of SC at sites with extensive neutrophil infiltrates after PMA or DNFB treatment. Our data support the view that SerpinB2 cross-linked into the $\mathrm{CE}$ and subsequently incorporated into the $\mathrm{SC}$ retains the ability to inhibit uPA, thereby limiting proteolytic degradation of the SC (an activity that most clearly manifests in inflammatory settings). uPA is up-regulated in keratinocytes and abundant in infiltrating neutrophils during skin inflammation. Plasmin(ogen) (the target of uPA) is found throughout the epidermis ${ }^{82}$ and the $\mathrm{SC}^{83}$ in inflammatory lesions, with plasmin also shown to induce psoriasiform skin inflammation. ${ }^{13}$

Differentiating keratinocytes constitutively express high levels of intracellular SerpinB2 in both humans and mice, with SerpinB2 secretion by keratinocytes shown to be inefficient. ${ }^{3,47}$ SerpinB $2^{-1-}$ mice showed no overt differences in the arrangement and structure of living keratinocyte layers in the epidermis, either in the resting state (in agreement with previous studies ${ }^{17}$ ) or after PMA treatment. Although a sizable literature has ascribed several activities to SerpinB2 and keratinocyte SerpinB2, we were unable to find evidence for a role for keratinocyte SerpinB2 in regulating IL-1 $\beta$ production, apoptosis, proteasome activity, or wound healing. Although keratinocytes can secrete active uPA during migration and wound healing, ${ }^{11,84,85}$ physiologically, SerpinB2's role in regulating this process would appear to be minimal. We recently reported efficient secretion of SerpinB2 by macrophages and transformed cells via microparticle formation, with SerpinB2 potentially externalized through association with phosphatidylserine (via annexins). Externalized SerpinB2 in these latter settings was able to inhibit tumor cell invasion/migration. ${ }^{10}$ However, to our knowledge, primary keratinocytes have not been reported to make microparticles, and phosphatidylserine externalization does not occur during keratinocyte differentiation ${ }^{86}$ or cornification. ${ }^{87}$ The physiological role of keratinocyte SerpinB2 would thus appear to be largely restricted to protection of the SC.

A role for SerpinB2 in regulating immunity has been well described, ${ }^{1,20-23}$ and is likely mediated by SerpinB2 expression in macrophages. Several observations argue that the $\operatorname{SerpinB2^{-1-}}$ mouse skin phenotype described herein is not associated with an immune-based activity: i) no significant differences were seen in anti-DNFB T-cell and antibody responses in SerpinB2 $2^{-/-}$and SerpinB2 $2^{+/+}$mice, ii) neutrophil recruitment after DNFB treatment was not significantly altered, iii) no significant recruitment of macrophages to the DNFB treatment sites or the epidermis was apparent, and iv) microarray analysis of skin suggested differences in SerpinB2 $2^{-1-}$ mice were largely associated with keratinocytes.

The SC defect in SerpinB2 $2^{-1-}$ mice suggests topically applied proinflammatory agents would penetrate more easily into the skin of $\operatorname{SerpinB2}^{-1-}$ mice (Figure 4B). This contention might prompt a reinterpretation of some experiments involving topical application of carcinogens (eg, DMBA [alias 7,12-Dimethylbenz(a)anthracene]) and tumor promoters (eg, PMA) in SerpinB2 $2^{-1-}$ mice $^{27,43}$ and mice overexpressing SerpinB2. ${ }^{28}$ The reduced and increased expression of SerpinB2 might simply result in increased and reduced, respectively, penetration of topically applied agents, rather than revealing an antiapoptotic role for keratinocyte SerpinB2. Several microarray studies have also shown up-regulation of SerpinB2 mRNA by oncogene products, such as $\operatorname{Ras}^{88-90}$ (eg, 33-fold up-regulation by H-Ras), ${ }^{91}$ p53, ${ }^{92}$ Raf,,${ }^{93,94}$ and E1A. ${ }^{95} p 63^{-1-}$ mice also show an approximately 10 -fold reduction in skin SerpinB2 mRNA expression. ${ }^{96}$ We have also confirmed the role of Ras and transformation in up-regulating SerpinB2 expression using quantitative RT-PCR, confocal microscopy, and reporter assays ${ }^{97,98}$ (Supplemental Figure S9). Care may thus also be warranted when interpreting studies using mice with genetically modified keratinocytes and topically applied carcinogens and tumor promoters, ${ }^{43,99-103}$ because keratinocytes in such mice may express different levels of SerpinB2, resulting in a modified SC and different penetration of these agents. Increased SerpinB2 expression was linked to the relative resistance of C57BL/6J mice to PMAmediated tumor promotion when compared with susceptible DBA/2J mice. ${ }^{104}$ Similar logic might also be applied to studies on contact dermatitis in genetically modified mice, such as those lacking certain NF- $\kappa$ B subunits, ${ }^{105}$ given the probable regulation of SerpinB2 by NF- $\kappa B .{ }^{106,107}$ Simple TEWL pretesting might thus be warranted in genetically modified mice to reveal differences in barrier function. 
SerpinB2 thus joins other Serpins reported to be important for the barrier function of the SC, including SerpinB3/ B4, ${ }^{108}$ SerpinB7, ${ }^{109}$ and SerpinA12. ${ }^{110}$ Interestingly, SerpinB2 was the only keratinocyte Serpin down-regulated in a publicly available study of nonlesional skin of allergic contact dermatitis patients ${ }^{111}$ (Supplemental Figure S10, A-C). A dysfunctional SC is also associated with atopic dermatitis, ${ }^{112}$ and analysis of three published and publicly available microarray studies ${ }^{113-115}$ revealed SerpinB2 is down-regulated in the skin (often nonlesional skin) of such patients (Supplemental Figure S10, D-F). Low keratinocyte SerpinB2 expression in humans might thus (as in mice) increase sensitivity to topical inflammatory agents and therefore predispose individuals to allergic contact dermatitis and/or atopic dermatitis.

\section{Acknowledgment}

We thank the animal house and the Histotechnology staff of QIMR Berghofer Medical Research Institute for their excellent support.

\section{Supplemental Data}

Supplemental material for this article can be found at http://dx.doi.org/10.1016/j.ajpath.2016.02.017.

\section{References}

1. Schroder WA, Major L, Suhrbier A: The role of SerpinB2 in immunity. Crit Rev Immunol 2011, 31:15-30

2. Major L, Schroder WA, Gardner J, Fish RJ, Suhrbier A: Human papilloma virus transformed CaSki cells constitutively express high levels of functional SerpinB2. Exp Cell Res 2011, 317:338-347

3. Risse BC, Brown H, Lavker RM, Pearson JM, Baker MS, Ginsburg D, Jensen PJ: Differentiating cells of murine stratified squamous epithelia constitutively express plasminogen activator inhibitor type 2 (PAI-2). Histochem Cell Biol 1998, 110:559-569

4. Kruithof EK, Baker MS, Bunn CL: Biological and clinical aspects of plasminogen activator inhibitor type 2. Blood 1995, 86:4007-4024

5. Medcalf RL, Stasinopoulos SJ: The undecided serpin: the ins and outs of plasminogen activator inhibitor type 2. FEBS J 2005, 272: 4858-4867

6. Medcalf RL: Plasminogen activator inhibitor type 2: still an enigmatic serpin but a model for gene regulation. Methods Enzymol 2011, 499: $105-134$

7. Gardiner EE, Medcalf RL: Is plasminogen activator inhibitor type 2 really a plasminogen activator inhibitor after all? J Thromb Haemost 2014, 12:1703-1705

8. Schuliga M: The inflammatory actions of coagulant and fibrinolytic proteases in disease. Mediators Inflamm 2015, 2015:437695

9. Fleetwood AJ, Achuthan A, Schultz H, Nansen A, Almholt K, Usher P, Hamilton JA: Urokinase plasminogen activator is a central regulator of macrophage three-dimensional invasion, matrix degradation, and adhesion. J Immunol 2014, 192:3540-3547

10. Schroder WA, Major LD, Le TT, Gardner J, Sweet MJ, Janciauskiene S, Suhrbier A: Tumor cell-expressed SerpinB2 is present on microparticles and inhibits metastasis. Cancer Med 2014, 3: $500-513$
11. Lund LR, Green KA, Stoop AA, Ploug M, Almholt K, Lilla J, Nielsen BS, Christensen IJ, Craik CS, Werb Z, Dano K, Romer J: Plasminogen activation independent of uPA and tPA maintains wound healing in gene-deficient mice. EMBO J 2006, 25:2686-2697

12. Deryugina EI, Quigley JP: Cell surface remodeling by plasmin: a new function for an old enzyme. J Biomed Biotechnol 2012, 2012: 564259

13. Li Q, Ke F, Zhang W, Shen X, Xu Q, Wang H, Yu XZ, Leng Q, Wang H: Plasmin plays an essential role in amplification of psoriasiform skin inflammation in mice. PLoS One 2011, 6:e16483

14. Xue M, Del Bigio MR: Acute tissue damage after injections of thrombin and plasmin into rat striatum. Stroke 2001, 32:2164-2169

15. Gliozzi M, Greenwell-Wild T, Jin W, Moutsopoulos NM, Kapsogeorgou E, Moutsopoulos HM, Wahl SM: A link between interferon and augmented plasmin generation in exocrine gland damage in Sjogren's syndrome. J Autoimmun 2013, 40:122-133

16. Judex MO, Mueller BM: Plasminogen activation/plasmin in rheumatoid arthritis: matrix degradation and more. Am J Pathol 2005, 166:645-647

17. Dougherty KM, Pearson JM, Yang AY, Westrick RJ, Baker MS, Ginsburg D: The plasminogen activator inhibitor-2 gene is not required for normal murine development or survival. Proc Natl Acad Sci U S A 1999, 96:686-691

18. von Heijne G, Liljestrom P, Mikus P, Andersson H, Ny T: The efficiency of the uncleaved secretion signal in the plasminogen activator inhibitor type 2 protein can be enhanced by point mutations that increase its hydrophobicity. J Biol Chem 1991, 266:15240-15243

19. Zhang S, Zou L, Yang T, Yang Y, Zhai Z, Xiao F, Wang C: The sGC activator inhibits the proliferation and migration, promotes the apoptosis of human pulmonary arterial smooth muscle cells via the up regulation of plasminogen activator inhibitor-2. Exp Cell Res 2015, 332:278-287

20. Schroder WA, Gardner J, Le TT, Duke M, Burke ML, Jones MK, McManus DP, Suhrbier A: SerpinB2 deficiency modulates Th1Th2 responses after schistosome infection. Parasite Immunol 2010, 32: 764-768

21. Schroder WA, Le TT, Major L, Street S, Gardner J, Lambley E, Markey K, MacDonald KP, Fish RJ, Thomas R, Suhrbier A: A physiological function of inflammation-associated SerpinB2 is regulation of adaptive immunity. J Immunol 2010, 184:2663-2670

22. Major LD, Partridge TS, Gardner J, Kent SJ, de Rose R, Suhrbier A, Schroder WA: Induction of SerpinB2 and Th1/Th2 modulation by SerpinB2 during lentiviral infections in vivo. PLoS One 2013, 8:e57343

23. Zhao A, Yang Z, Sun R, Grinchuk V, Netzel-Arnett S, Anglin IE, Driesbaugh KH, Notari L, Bohl JA, Madden KB, Urban JF Jr, Antalis TM, Shea-Donohue T: SerpinB2 is critical to Th2 immunity against enteric nematode infection. J Immunol 2013, 190:5779-5787

24. Norling LV, Dalli J: Microparticles are novel effectors of immunity. Curr Opin Pharmacol 2013, 13:570-575

25. Greten FR, Arkan MC, Bollrath J, Hsu LC, Goode J, Miething C, Goktuna SI, Neuenhahn M, Fierer J, Paxian S, Van Rooijen N, Xu Y, O'Cain T, Jaffee BB, Busch DH, Duyster J, Schmid RM, Eckmann L, Karin M: NF-kappaB is a negative regulator of IL-1beta secretion as revealed by genetic and pharmacological inhibition of IKKbeta. Cell 2007, 130:918-931

26. Chuang SY, Yang CH, Chou CC, Chiang YP, Chuang TH, Hsu LC: TLR-induced PAI-2 expression suppresses IL-1beta processing via increasing autophagy and NLRP3 degradation. Proc Natl Acad Sci U S A 2013, 110:16079-16084

27. Tonnetti L, Netzel-Arnett S, Darnell GA, Hayes T, Buzza MS, Anglin IE, Suhrbier A, Antalis TM: SerpinB2 protection of retinoblastoma protein from calpain enhances tumor cell survival. Cancer Res 2008, 68:5648-5657

28. Zhou HM, Bolon I, Nichols A, Wohlwend A, Vassalli JD: Overexpression of plasminogen activator inhibitor type 2 in basal keratinocytes enhances papilloma formation in transgenic mice. Cancer Res 2001, 61:970-976 
29. Delhase M, Kim SY, Lee H, Naiki-Ito A, Chen Y, Ahn ER, Murata K, Kim SJ, Lautsch N, Kobayashi KS, Shirai T, Karin M, Nakanishi M: TANK-binding kinase 1 (TBK1) controls cell survival through PAI-2/serpinB2 and transglutaminase 2. Proc Natl Acad Sci U S A 2012, 109:E177-E186

30. Boncela J, Przygodzka P, Papiewska-Pajak I, Wyroba E, Cierniewski CS: Association of plasminogen activator inhibitor type 2 (PAI-2) with proteasome within endothelial cells activated with inflammatory stimuli. J Biol Chem 2011, 286:43164-43171

31. Braungart E, Magdolen V, Degitz K: Retinoic acid upregulates the plasminogen activator system in human epidermal keratinocytes. J Invest Dermatol 2001, 116:778-784

32. Lyons-Giordano B, Loskutoff D, Chen CS, Lazarus G, Keeton M, Jensen PJ: Expression of plasminogen activator inhibitor type 2 in normal and psoriatic epidermis. Histochemistry 1994, 101:105-112

33. Schaefer BM, Jaeger C, Drepper E, Kramer MD: Plasminogen activation in bullous pemphigoid immunohistology reveals urokinase type plasminogen activator, its receptor and plasminogen activator inhibitor type-2 in lesional epidermis. Autoimmunity 1996, 23: $155-164$

34. Bechtel MJ, Schaefer BM, Kramer MD: Plasminogen activator inhibitor type-2 in the lesional epidermis of lupus erythematosus. Br J Dermatol 1996, 134:411-419

35. Oji V, Oji ME, Adamini N, Walker T, Aufenvenne K, Raghunath M, Traupe H: Plasminogen activator inhibitor-2 is expressed in different types of congenital ichthyosis: in vivo evidence for its cross-linking into the cornified cell envelope by transglutaminase-1. Br J Dermatol 2006, 154:860-867

36. Stacey MC, Mata SD: Lower levels of PAI-2 may contribute to impaired healing in venous ulcers: a preliminary study. Cardiovasc Surg 2000, 8:381-385

37. Kessler-Becker D, Smola S, Krieg T, Eckes B: High plasminogen activator inhibitor type 2 expression is a hallmark of scleroderma fibroblasts in vitro. Exp Dermatol 2004, 13:708-714

38. Heda GD, Roberts LK: Role of tissue-type plasminogen activator in salicylic acid-induced sloughing of human corn tissue. J Am Podiatr Med Assoc 2008, 98:345-352

39. Jang S, Yang TH, An EJ, Yoon HK, Sohn KC, Cho AY, Ryu EK, Park YS, Yoon TY, Lee JH, Kim CD: Role of plasminogen activator inhibitor-2 (PAI-2) in keratinocyte differentiation. J Dermatol Sci 2010, 59:25-30

40. Lian X, Yang T: Plasminogen activator inhibitor 2: expression and role in differentiation of epidermal keratinocyte. Biol Cell 2004, 96: $109-116$

41. Lyons-Giordano B, Lazarus GS: Calcium modulates the expression of urokinase plasminogen activator and plasminogen activator inhibitor 2 by human keratinocytes. Exp Dermatol 1994, 3:85-88

42. Hibino T, Matsuda Y, Takahashi T, Goetinck PF: Suppression of keratinocyte proliferation by plasminogen activator inhibitor-2. J Invest Dermatol 1999, 112:85-90

43. Rushworth LK, Kidger AM, Delavaine L, Stewart G, van Schelven S, Davidson J, Bryant CJ, Caddye E, East P, Caunt CJ, Keyse SM: Dual-specificity phosphatase 5 regulates nuclear ERK activity and suppresses skin cancer by inhibiting mutant Harvey-Ras (HRasQ61L)driven SerpinB2 expression. Proc Natl Acad Sci U S A 2014, 111: 18267-18272

44. Reinartz J, Schaefer B, Bechtel MJ, Kramer MD: Plasminogen activator inhibitor type-2 (PAI-2) in human keratinocytes regulates pericellular urokinase-type plasminogen activator. Exp Cell Res 1996, 223:91-101

45. Zhang C, Ponugoti B, Tian C, Xu F, Tarapore R, Batres A, Alsadun S, Lim J, Dong G, Graves DT: FOXO1 differentially regulates both normal and diabetic wound healing. J Cell Biol 2015, 209: 289-303

46. Risse BC, Chung NM, Baker MS, Jensen PJ: Evidence for intracellular cleavage of plasminogen activator inhibitor type 2 (PAI-2) in normal epidermal keratinocytes. J Cell Physiol 2000, 182:281-289
47. Jensen PJ, Wu Q, Janowitz P, Ando Y, Schechter NM: Plasminogen activator inhibitor type 2: an intracellular keratinocyte differentiation product that is incorporated into the cornified envelope. Exp Cell Res 1995, 217:65-71

48. Robinson NA, Lapic S, Welter JF, Eckert RL: S100A11, S100A10, annexin I, desmosomal proteins, small proline-rich proteins, plasminogen activator inhibitor-2, and involucrin are components of the cornified envelope of cultured human epidermal keratinocytes. J Biol Chem 1997, 272:12035-12046

49. Eckhart L, Lippens S, Tschachler E, Declercq W: Cell death by cornification. Biochim Biophys Acta 2013, 1833:3471-3480

50. Kalinin A, Marekov LN, Steinert PM: Assembly of the epidermal cornified cell envelope. J Cell Sci 2001, 114:3069-3070

51. Gaspari AA, Katz SI: Contact hypersensitivity. Curr Protoc Immunol 2001, ch 4:Unit 4.2

52. Poo YS, Nakaya H, Gardner J, Larcher T, Schroder WA, Le TT, Major LD, Suhrbier A: CCR2 deficiency promotes exacerbated chronic erosive neutrophil-dominated chikungunya virus arthritis. J Virol 2014, 88:6862-6872

53. Kaplan DH, Igyarto BZ, Gaspari AA: Early immune events in the induction of allergic contact dermatitis. Nat Rev Immunol 2012, 12: $114-124$

54. Christensen AD, Haase C: Immunological mechanisms of contact hypersensitivity in mice. APMIS 2012, 120:1-27

55. Christensen AD, Skov S, Haase C: The role of neutrophils and G-CSF in DNFB-induced contact hypersensitivity in mice. Immun Inflamm Dis 2014, 2:21-34

56. Bechtel MJ, Wysocki NS, Heidtmann A, Stark HJ, Fusenig N, Kramer MD, Schaefer BM: Plasminogen activator inhibitor type 2 is expressed in keratinocytes during re-epithelialization of epidermal defects. Br J Dermatol 1998, 138:22-28

57. Jensen PH, Cressey LI, Gjertsen BT, Madsen P, Mellgren G, Hokland P, Gliemann J, Doskeland SO, Lanotte M, Vintermyr OK: Cleaved intracellular plasminogen activator inhibitor 2 in human myeloleukaemia cells is a marker of apoptosis. Br J Cancer 1994, 70: $834-840$

58. Zhang EY, Chen AY, Zhu BT: Mechanism of dinitrochlorobenzeneinduced dermatitis in mice: role of specific antibodies in pathogenesis. PLoS One 2009, 4:e7703

59. Warbrick EV, Dearman RJ, Kimber I: Induced changes in total serum $\operatorname{IgE}$ concentration in the brown Norway rat: potential for identification of chemical respiratory allergens. J Appl Toxicol 2002, 22:1-11

60. Watanabe H, Gaide O, Petrilli V, Martinon F, Contassot E, Roques S, Kummer JA, Tschopp J, French LE: Activation of the IL-1betaprocessing inflammasome is involved in contact hypersensitivity. J Invest Dermatol 2007, 127:1956-1963

61. Lavker RM, Risse B, Brown H, Ginsburg D, Pearson J, Baker MS, Jensen PJ: Localization of plasminogen activator inhibitor type 2 (PAI-2) in hair and nail: implications for terminal differentiation. J Invest Dermatol 1998, 110:917-922

62. Gan H, Lee J, Ren F, Chen M, Kornfeld H, Remold HG: Mycobacterium tuberculosis blocks crosslinking of annexin-1 and apoptotic envelope formation on infected macrophages to maintain virulence. Nat Immunol 2008, 9:1189-1197

63. Fish RJ, Kruithof EK: Evidence for serpinB2-independent protection from TNF-alpha-induced apoptosis. Exp Cell Res 2006, 312:350-361

64. Fan J, Zhang YQ, Li P, Hou M, Tan L, Wang X, Zhu YS: Interaction of plasminogen activator inhibitor-2 and proteasome subunit, beta type 1. Acta Biochim Biophys Sin (Shanghai) 2004, 36:42-46

65. Nakaya HI, Gardner J, Poo YS, Major L, Pulendran B, Suhrbier A: Gene profiling of Chikungunya virus arthritis in a mouse model reveals significant overlap with rheumatoid arthritis. Arthritis Rheum 2012, 64:3553-3563

66. Denda M: Newly discovered olfactory receptors in epidermal keratinocytes are associated with proliferation, migration, and re-epithelialization of keratinocytes. J Invest Dermatol 2014, 134: $2677-2679$ 
67. Busse D, Kudella P, Gruning NM, Gisselmann G, Stander S, Luger T, Jacobsen F, Steinstrasser L, Paus R, Gkogkolou P, Bohm M, Hatt H, Benecke H: A synthetic sandalwood odorant induces wound-healing processes in human keratinocytes via the olfactory receptor OR2AT4. J Invest Dermatol 2014, 134:2823-2832

68. Lammers G, Roth G, Heck M, Zengerle R, Tjabringa GS, Versteeg EM, Hafmans T, Wismans R, Reinhardt DP, Verwiel ET, Zeeuwen PL, Schalkwijk J, Brock R, Daamen WF, van Kuppevelt TH: Construction of a microstructured collagen membrane mimicking the papillary dermis architecture and guiding keratinocyte morphology and gene expression. Macromol Biosci 2012, 12:675-691

69. Schroeder LM: Olfactory recognition of nonhosts aspen and birch by conifer bark beetles Tomicus piniperda and Hylurgops palliatus. J Chem Ecol 1992, 18:1583-1593

70. Park J, Chang J, Kim M, Kim J, Kim S-K: Gene expression profiling in the human keratinocyte cell line, hacat exposed to urushiol isolated from sap of Korean lacquer tree (Rhus verniciflua Stokes). Mol Cell Toxicol 2010, 6:79-86

71. Peng W, Novak N: Pathogenesis of atopic dermatitis. Clin Exp Allergy 2015, 45:566-574

72. Kottner J, Lichterfeld A, Blume-Peytavi U: Transepidermal water loss in young and aged healthy humans: a systematic review and metaanalysis. Arch Dermatol Res 2013, 305:315-323

73. Lund LR, Eriksen J, Ralfkiaer E, Romer J: Differential expression of urokinase-type plasminogen activator, its receptor, and inhibitors in mouse skin after exposure to a tumor-promoting phorbol ester. J Invest Dermatol 1996, 106:622-630

74. Stanley PL, Steiner S, Havens M, Tramposch KM: Mouse skin inflammation induced by multiple topical applications of 12-Otetradecanoylphorbol-13-acetate. Skin Pharmacol 1991, 4:262-271

75. Furstenberger G, Berry DL, Sorg B, Marks F: Skin tumor promotion by phorbol esters is a two-stage process. Proc Natl Acad Sci U S A 1981, 78:7722-7726

76. Rundhaug JE, Fischer SM: Molecular mechanisms of mouse skin tumor promotion. Cancers (Basel) 2010, 2:436-482

77. Parkinson EK, Grabham P, Emmerson A: A subpopulation of cultured human keratinocytes which is resistant to the induction of terminal differentiation-related changes by phorbol, 12-myristate, 13acetate: evidence for an increase in the resistant population following transformation. Carcinogenesis 1983, 4:857-861

78. de Veer SJ, Furio L, Harris JM, Hovnanian A: Proteases and proteomics: cutting to the core of human skin pathologies. Proteomics Clin Appl 2014, 8:389-402

79. Cochran BJ, Gunawardhana LP, Vine KL, Lee JA, Lobov S, Ranson M: The CD-loop of PAI-2 (SERPINB2) is redundant in the targeting, inhibition and clearance of cell surface uPA activity. BMC Biotechnol 2009, 9:43

80. Gyetko MR, Aizenberg D, Mayo-Bond L: Urokinase-deficient and urokinase receptor-deficient mice have impaired neutrophil antimicrobial activation in vitro. J Leukoc Biol 2004, 76:648-656

81. Cork MJ, Danby SG, Vasilopoulos Y, Hadgraft J, Lane ME, Moustafa M, Guy RH, Macgowan AL, Tazi-Ahnini R, Ward SJ: Epidermal barrier dysfunction in atopic dermatitis. J Invest Dermatol 2009, 129:1892-1908

82. Gissler HM, Frank R, Kramer MD: Immunohistochemical characterization of the plasminogen activator system in psoriatic epidermis. Br J Dermatol 1993, 128:612-618

83. Voegeli R, Rawlings AV, Doppler S, Heiland J, Schreier T: Profiling of serine protease activities in human stratum corneum and detection of a stratum corneum tryptase-like enzyme. Int J Cosmet Sci 2007, 29:191-200

84. Botta A, Delteil F, Mettouchi A, Vieira A, Estrach S, Negroni L, Stefani C, Lemichez E, Meneguzzi G, Gagnoux-Palacios L: Confluence switch signaling regulates ECM composition and the plasmin proteolytic cascade in keratinocytes. J Cell Sci 2012, 125:4241-4252

85. Simone TM, Higgins CE, Czekay RP, Law BK, Higgins SP, Archambeault J, Kutz SM, Higgins PJ: SERPINE1: a molecular switch in the proliferation-migration dichotomy in wound-"activated" keratinocytes. Adv Wound Care 2014, 3:281-290

86. Kielar D, Kaminski WE, Liebisch G, Piehler A, Wenzel JJ, Mohle C, Heimerl S, Langmann T, Friedrich SO, Bottcher A, Barlage S, Drobnik W, Schmitz G: Adenosine triphosphate binding cassette $(\mathrm{ABC})$ transporters are expressed and regulated during terminal keratinocyte differentiation: a potential role for ABCA7 in epidermal lipid reorganization. J Invest Dermatol 2003, 121:465-474

87. Melino G, Knight RA, Nicotera P: How many ways to die? how many different models of cell death? Cell Death Differ 2005, 12 Suppl 2:1457-1462

88. Brem R, Certa U, Neeb M, Nair AP, Moroni C: Global analysis of differential gene expression after transformation with the $\mathrm{v}-\mathrm{H}$-ras oncogene in a murine tumor model. Oncogene 2001, 20:2854-2858

89. Cohen RL, Niclas J, Lee WM, Wun TC, Crowley CW, Levinson AD, Sadler JE, Shuman MA: Effects of cellular transformation on expression of plasminogen activator inhibitors 1 and 2: evidence for independent regulation. J Biol Chem 1989, 264:8375-8383

90. Dear AE, Medcalf RL: The novel anti-tumour agent oxamflatin differentially regulates urokinase and plasminogen activator inhibitor type 2 expression and inhibits urokinase-mediated proteolytic activity. Biochim Biophys Acta 2000, 1492:15-22

91. Hanson JL, Hawke NA, Kashatus D, Baldwin AS: The nuclear factor kappaB subunits RelA/p65 and c-Rel potentiate but are not required for Ras-induced cellular transformation. Cancer Res 2004, 64: $7248-7255$

92. McMurray HR, Sampson ER, Compitello G, Kinsey C, Newman L, Smith B, Chen SR, Klebanov L, Salzman P, Yakovlev A, Land H: Synergistic response to oncogenic mutations defines gene class critical to cancer phenotype. Nature 2008, 453:1112-1116

93. Heinrich J, Bosse M, Eickhoff H, Nietfeld W, Reinhardt R, Lehrach H, Moelling K: Induction of putative tumor-suppressing genes in Rat-1 fibroblasts by oncogenic Raf- 1 as evidenced by robot-assisted complex hybridization. J Mol Med (Berl) 2000, 78: 380-388

94. Schulze A, Nicke B, Warne PH, Tomlinson S, Downward J: The transcriptional response to Raf activation is almost completely dependent on mitogen-activated protein kinase kinase activity and shows a major autocrine component. Mol Biol Cell 2004, 15: $3450-3463$

95. Fernandez-Soria V, Lleonart ME, Diaz-Fuertes M, Villuendas R, Sanchez-Prieto R, Fabra A, Ramon YCS: Adenovirus E1A orchestrates the urokinase-plasminogen activator system and upregulates PAI-2 expression, supporting a tumor suppressor effect. Int J Oncol 2006, 28:143-148

96. Koster MI, Kim S, Huang J, Williams T, Roop DR: TAp63alpha induces AP-2gamma as an early event in epidermal morphogenesis. Dev Biol 2006, 289:253-261

97. Schuster WA, Medcalf RL, Kruithof KO: Localization and characterization of a retinoic acid response-like element in the plasminogen activator inhibitor-2 gene promoter. Fibrinolysis 1994, 8:113-119

98. Schroder WA, Buck M, Cloonan N, Hancock JF, Suhrbier A, Sculley T, Bushell G: Human Sin1 contains Ras-binding and pleckstrin homology domains and suppresses Ras signalling. Cell Signal 2007, 19:1279-1289

99. Li Q, Sambandam SA, Lu HJ, Thomson A, Kim SH, Lu H, Xin Y, Lu Q: 14-3-3sigma and p63 play opposing roles in epidermal tumorigenesis. Carcinogenesis 2011, 32:1782-1788

100. Inoue S, Hao Z, Elia AJ, Cescon D, Zhou L, Silvester J, Snow B, Harris IS, Sasaki M, Li WY, Itsumi M, Yamamoto K, Ueda T, Dominguez-Brauer C, Gorrini C, Chio II, Haight J, You-Ten A, McCracken S, Wakeham A, Ghazarian D, Penn LJ, Melino G, Mak TW: Mule/Huwe1/Arf-BP1 suppresses Ras-driven tumorigenesis by preventing c-Myc/Miz1-mediated down-regulation of $\mathrm{p} 21$ and p15. Genes Dev 2013, 27:1101-1114

101. Hayashi K, Momoi Y, Tanuma N, Kishimoto A, Ogoh H, Kato H, Suzuki M, Sakamoto Y, Inoue Y, Nomura M, Kiyonari H, 
Sakayori M, Fukamachi K, Kakugawa Y, Yamashita Y, Ito S, Sato I, Suzuki A, Nishio M, Suganuma M, Watanabe T, Shima H: Abrogation of protein phosphatase 6 promotes skin carcinogenesis induced by DMBA. Oncogene 2015, 34:4647-4655

102. Kiss A, Koppel AC, Anders J, Cataisson C, Yuspa SH, Blumenberg M, Efimova T: Keratinocyte p38delta loss inhibits Rasinduced tumor formation, while systemic p38delta loss enhances skin inflammation in the early phase of chemical carcinogenesis in mouse skin. Mol Carcinog 2015, 55:563-574

103. Schindler EM, Hindes A, Gribben EL, Burns CJ, Yin Y, Lin MH, Owen RJ, Longmore GD, Kissling GE, Arthur JS, Efimova T: p38delta Mitogen-activated protein kinase is essential for skin tumor development in mice. Cancer Res 2009, 69:4648-4655

104. Riggs PK, Angel JM, Abel EL, DiGiovanni J: Differential gene expression in epidermis of mice sensitive and resistant to phorbol ester skin tumor promotion. Mol Carcinog 2005, 44:122-136

105. Grinberg-Bleyer $Y$, Dainichi $T$, Oh H, Heise N, Klein U, Schmid RM, Hayden MS, Ghosh S: Cutting edge: NF-kappaB p65 and c-Rel control epidermal development and immune homeostasis in the skin. J Immunol 2015, 194:2472-2476

106. Varro A, Noble PJ, Pritchard DM, Kennedy S, Hart CA, Dimaline R, Dockray GJ: Helicobacter pylori induces plasminogen activator inhibitor 2 in gastric epithelial cells through nuclear factor-kappaB and RhoA: implications for invasion and apoptosis. Cancer Res 2004, 64: $1695-1702$

107. Mahony D, Kalionis B, Antalis TM: Plasminogen activator inhibitor type-2 (PAI-2) gene transcription requires a novel NF-kappaBlike transcriptional regulatory motif. Eur J Biochem 1999, 263: $765-772$

108. Sivaprasad U, Kinker KG, Ericksen MB, Lindsey M, Gibson AM, Bass SA, Hershey NS, Deng J, Medvedovic M, Khurana Hershey GK: SERPINB3/B4 contributes to early inflammation and barrier dysfunction in an experimental murine model of atopic dermatitis. J Invest Dermatol 2015, 135:160-169
109. Kubo A, Shiohama A, Sasaki T, Nakabayashi K, Kawasaki H, Atsugi T, Sato S, Shimizu A, Mikami S, Tanizaki H, Uchiyama M, Maeda T, Ito T, Sakabe J, Heike T, Okuyama T, Kosaki R, Kosaki K, Kudoh J, Hata K, Umezawa A, Tokura Y, Ishiko A, Niizeki H, Kabashima K, Mitsuhashi Y, Amagai M: Mutations in SERPINB7, encoding a member of the serine protease inhibitor superfamily, cause Nagashima-type palmoplantar keratosis. Am J Hum Genet 2013, 93: 945-956

110. Toulza E, Mattiuzzo NR, Galliano MF, Jonca N, Dossat C, Jacob D, de Daruvar A, Wincker P, Serre G, Guerrin M: Large-scale identification of human genes implicated in epidermal barrier function. Genome Biol 2007, 8:R107

111. Pedersen MB, Skov L, Menne T, Johansen JD, Olsen J: Gene expression time course in the human skin during elicitation of allergic contact dermatitis. J Invest Dermatol 2007, 127:2585-2595

112. Elias PM, Wakefield JS: Mechanisms of abnormal lamellar body secretion and the dysfunctional skin barrier in patients with atopic dermatitis. J Allergy Clin Immunol 2014, 134:781-791.e1

113. Gittler JK, Shemer A, Suarez-Farinas M, Fuentes-Duculan J, Gulewicz KJ, Wang CQ, Mitsui H, Cardinale I, de Guzman Strong C, Krueger JG, Guttman-Yassky E: Progressive activation of $\mathrm{T}(\mathrm{H})$ $2 / \mathrm{T}(\mathrm{H}) 22$ cytokines and selective epidermal proteins characterizes acute and chronic atopic dermatitis. J Allergy Clin Immunol 2012, 130:1344-1354

114. Suarez-Farinas M, Tintle SJ, Shemer A, Chiricozzi A, Nograles K, Cardinale I, Duan S, Bowcock AM, Krueger JG, Guttman-Yassky E: Nonlesional atopic dermatitis skin is characterized by broad terminal differentiation defects and variable immune abnormalities. J Allergy Clin Immunol 2011, 127:954-964.e1-4

115. Guttman-Yassky E, Suarez-Farinas M, Chiricozzi A, Nograles KE, Shemer A, Fuentes-Duculan J, Cardinale I, Lin P, Bergman R, Bowcock AM, Krueger JG: Broad defects in epidermal cornification in atopic dermatitis identified through genomic analysis. J Allergy Clin Immunol 2009, 124:1235-1244.e58 